\title{
DANZA EXPERIMENTAL CONTEMPORANEA Creación de Mutanza D.E.C.
}

\section{Por: Claudia Mallarino Flórez*}

El propósito general de nuestro discurso dancístico es diseñar espacios de comunicación con el contexto; de interlocución con el "otro"; de interpretación del fenómeno vital y de construcción de procesos pedagógico-didácticos para acceder al conocimiento desde la experiencia directa de la interacción corporal con el entorno.

Mutanza DEC nace en 1997, por iniciativa personal y de alumnos y egresados de la Facultad de Educación Física: de la UPN, así como de algunos enamorados de la Danza, ajenos a la Facultad, pero cercanos a nuestros intereses. El propósito fundamental de este grupo de personas, en su doble condición de futuros bailarines y maestros, es trabajar el lenguaje de la Danza, como una posibilidad de identificación de la propia dimensión corporal.

Asumir el lenguaje de movimiento como una opción real de comunicación, genera como necesidad en el grupo definir un discurso expresivo, que nos identifique como artistas cuyo encargo social es leer el contexto para dialogar con él. Además, satisfacer la necesidad de crear ámbitos alternativos de interpretación del mundo, diferentes a los puramente racionales y alimentados por la facultad simbólica del movimiento.

\section{Propuesta de elaboración coreo gráfica}

Al cumplir seis meses reunidos aprendiendo diferentes lenguajes expresivos de danza, el grupo decide empezar a realizar un trabajo coreográfico que sirva de pretexto para comunicar la intención discursiva que surge del interés que como maestros y futuros docentes tienen, a partir de la profunda convicción de que hacer arte no es solamente desempeñarse con maestría en una técnica, sino dialogar con la sociedad ofreciendo canales de interpretación del mundo, diferentes a los cotidianos.

La primera tarea colectiva es decidir la temática que plantea la obra. El grupo se reúne, aporta ideas arguméntales, estudia el material elaborado por la maestra mexicana Patricia Cardona (Texto y Vídeo), "La Percepción del Espectador", lee documentos de diferentes creadores en artes escénicas como Pina Bausch, Doris Humphrey, Eugenio Barba, y realiza sesiones de estudio de videos para conocer diferentes propuestas artísticas. Paralelo a este proceso, el grupo empieza a asistir a teatros, exposiciones y conciertos que le permiten leer el contexto y definir una posible temática que interese a la sociedad y con la cual se identifiquen como colombianos y como maestros.

Después de este ejercicio de identificación de significados e interpretación de la experiencia y la vivencia social de nuestra comunidad, toma la decisión de trabajar la "comunicación" como temática nuclear, y se impone la tarea de hacer propuestas y estudiarlas para identificar intereses comunes y desarrollar una línea argumental que traduzca su intención discursiva.

El argumento, "construcción de un lenguaje colectivo como mensaje de paz", plantea la necesidad de definir momentos escénicos que recreen un posible camino de acceso al diálogo colectivo. La propuesta argumental se define como la búsqueda de una

\footnotetext{
*Profesora Facultad de Educación Física U.P.N.
} 
posibilidad para construir una comprensión social mutua, desde la verificación de la imposibilidad de comunicar a través de lenguajes impuestos y homogeneizantes o de lenguajes tan personales que no dan la opción de intercambiar significados.

El argumento de la pieza se estructura en tres partes, un prólogo y un epílogo así:

\section{Prólogo}

Nacimiento social dentro de una estructura rígida, liberación ficticia y confirmación de residuos de sometimiento.

\section{Primera Parte}

Sociedad normatizada, que obedece a reglas sociales pre-establecidas, encadenada a una estructura que delimita una sectorización de clases, en donde comunicarse obedece a una pretensión discursiva impuesta desde el exterior, para garantizar el cumplimiento de intereses ajenos al grupo social y en donde las posibilidades de diálogo están sujetas a transmitir los mensajes y a cumplir con las intenciones de un grupo dominante.

\section{Transición}

Se elimina la sectorización por clases sociales, pero sigue primando una estructura eminentemente masculina. El diálogo entre hombre y mujer es de sometimiento, condicionado por la supervivencia de la mujer a partir del soporte masculino. La mujer va ganando espacios de diálogo con el hombre, plantea formas discursivas más activas; sin embargo, es él la base de sustentación de la estructura social.

\section{Segunda Parte}

Liberación femenina y creación de núcleos sociales que plantean discursos particulares, eliminando la posibilidad de construir un lenguaje social común y un espacio de comprensión mutua.

\section{Tercera Parte}

Construcción colectiva de un lenguaje común, en donde reconocer al "otro" obedece a la intención social de multiplicar los canales de comunicación para enriquecer el discurso social. Ampliar las posibilidades de expresión de la naturaleza particular de los sujetos, en la búsqueda constante de espacios de interacción, es aumentar el vocabulario cultural.

\section{Epílogo}

Mensaje de paz: El lenguaje colectivo como una propuesta de convivencia social madura.

Una vez planteado el argumento, se determina la dinámica de trabajo que constituye el proceso de implementación de la propuesta artística en tres momentos: Formación Técnica, Construcción del Discurso Corporal y Puesta en Escena.

La dinámica de la realización, desarrollo e implementación de cada momento, parte de la definición de necesidades, expectativas y objetivos determinados por el grupo. 


\section{Formación técnica}

\section{Sintaxis del movimiento}

La formación técnica se refiere al entrenamiento que posibilita la definición del discurso corporal entendido no solamente como la adquisición de un patrón sistematizado de movimiento, sino como la definición del lenguaje a través del cual el artista bailarín construye una forma particular de interacción y diálogo con la sociedad, para evidenciar su rol activo en el ámbito de manifestación de las características propias de su cultura y del momento histórico en que vive.

La formación técnica es un proceso que dura toda la vida del artista, porque es el espacio diario de encuentro con esa corporalidad que tiene una naturaleza dinámica y que en cada etapa de su existencia ofrece niveles distintos de madurez para entablar comunicación con el "otro", el escucha, también cambiante.

Esta formación se plantea desde dos terrenos distintos: La Técnica Corporal, referida a la educación del cuerpo como estructura psicofísica en donde se realiza el gesto corporal y cuyo logro permite la ejecución eficiente, estética y funcional del movimiento, dentro de un programa de acciones sistematizadas que denominamos Técnica de movimiento.

La formación técnica requiere del desarrollo de la Sintaxis del movimiento, integrada por el vocabulario de movimiento (palabras corporales), la gramática de movimiento (escritura de las palabras o formas correctas de ejecución del gesto; es decir, funcionales y adaptadas a las características del ejecutante) y la ortografía de movimiento (posibilidades de combinación de las palabras corporales para elaborar composiciones de movimiento, acentos, énfasis, detenciones, cadencias), de la Semántica del movimiento (sentido y significado del gesto corporal) y de la Pragmática de movimiento (uso del lenguaje corporal).

La Semántica y la Pragmática del Movimiento se evidencian en la Construcción del Discurso Corporal y en la Puesta en Escena, que son los dos momentos finales del proceso de formación.

El vocabulario de movimiento, la gramática, la ortografía y la sintaxis forman parte del proceso inicial de formación del bailarín y están definidos y organizados por el maestro de danza, el coreógrafo con quien se trabaja o el director académico de la escuela que escoge el futuro artista para educarse.

En nuestro caso particular, la clase de danza contemporánea es dirigida por mí; mi desempeño como ejecutante y artista tiene un nivel profesional y mi experiencia como docente me permite diseñar y sistematizar procesos de enseñanza - aprendizaje de lenguajes de la danza.

Los alumnos, sin embargo, son los que deciden los lenguajes que les interesa trabajar y aprender, obedeciendo al objetivo argumental planteado para la pieza en elaboración. Así también, las dinámicas didácticas que se ajustan mejor a sus condiciones corporales particulares, por lo cual no es raro ver en el mismo espacio de clase formas distintas de desarrollo de los contenidos. 


\section{Construcción del discurso corporal}

\section{Semántica del movimiento}

La Construcción del Discurso Corporal es el paso de la técnica como finalidad del proceso de formación del bailarín a la técnica como instrumento de construcción de un lenguaje particular, que gracias a sus características específicas (sintaxis) permite darle al gesto corporal un sentido; es decir, convertirlo en significante (semántica) para que el interlocutor (público) le asigne significados partiendo de la lectura que hace de la propuesta escénica, desde su experiencia, su memoria de vida y la comprensión del contexto simbólico que plantea la obra (pragmática).

El Discurso Corporal que pone en evidencia la intención comunicativa de Mutanza es el resultado de la implementación de talleres de improvisación y de la aplicación de un sistema de elaboración de movimiento propuesto por mí e interpretado por cada bailarín con el propósito de crear una gestual corporal que traduzca la necesidad individual de expresarse, en la exigencia colectiva de crear espacios de comprensión mutua como una alternativa de interacción y diálogo que conduzca a la convivencia pacífica de nuestra sociedad.

Cada momento de la obra compuesta por el grupo, tiene implícito un lenguaje de movimiento que expresa la intención argumental definida para cada parte. En la Propuesta de Elaboración Coreográfica se hizo una breve descripción de las partes que integran la obra. Haré ahora una enunciación del carácter específico del discurso corporal que alimenta cada momento de la pieza "A Golpe de Danza".

\section{Primera parte:}

El lenguaje de movimiento es orientado por la profesora y se impone la condición de una ejecución homogénea y sincronizada.

\section{Segunda parte:} forman.

El lenguaje de movimiento es definido por cada uno de los núcleos sociales que se

\section{Tercera parte:}

El lenguaje de movimiento es elaborado en su totalidad por el grupo en un proceso de construcción colectiva.

El grupo quiere sugerir con la modificación de discursos, que hablar usando semánticas particulares si bien da la posibilidad de expresarse con libertad no ofrece opciones reales de comunicación social, ya que no tiene en cuenta al "otro" como inter-locutor con necesidades e intereses equivalentes. 


\section{Puesta en escena}

\section{Pragmática del Movimiento}

La Puesta en Escena de una obra de danza se refiere al momento de llevarla al escenario para presentarla al público. En la Danza Contemporánea el escenario puede ser cualquier espacio físico que se ajuste a las necesidades de dimensión y situación (si se quiere recrear una atmósfera social específica: mercado, feria, hospital etc) ya que como lenguaje social, plantea temáticas socio-culturales de diversa índole, lo que implica que el escenario ya no es solamente el lugar en donde se baila. Es un elemento más a considerar en la propuesta artística del coreógrafo, pues su escogencia sitúa al público en un contexto determinado para recibir el mensaje que quiere comunicar la pieza.

La elaboración escénica de una pieza de danza implica atender a varios aspectos:

- Definición de un vestuario que interprete las características del grupo social que se representa.

- Definición de la escenografía como el marco contextual en que se ubican los bailarines.

- Creación de la atmósfera escénica a partir de la iluminación del espacio, usando la luz como elemento escenográfico que define intenciones concretas de ubicación de la atención del público en momentos y lugares del espacio predeterminados por el objetivo argumental, así como de elementos presentes para simbolizar el sentido del discurso propuesto.

- Definición de la música usada como interlocutor del movimiento, para reproducir sensaciones auditivas que convoquen al público a estados emocionales particulares de la intención del discurso gestual, originada en la creación de la pieza y parte fundamental de la memoria sensorial del auditorio.

- La ubicación de los bailarines en el escenario no obedece a llenar el espacio, sino a definir ámbitos de acción que igualmente determinan intenciones precisas del discurso. Un bailarín situado atrás o en la parte frontal puede estar planteando la relevancia o la poca importancia del personaje en ese momento.

El pre-estreno de la pieza "A Golpe de Danza”, se llevó a cabo en el coliseo de la Universidad Pedagógica Nacional en noviembre de 1998, porque la primera intención al salir a escena era verificar la identificación del público (de todas las edades, de la universidad y de afuera) con la propuesta como mensaje social de paz, lo que implicaba un lugar abierto, con entrada libre y en donde las personas sintieran una atmósfera familiar (espacio no formal como un teatro) para expresar sus sentimientos y reacciones al mensaje, libremente.

El resultado de la primera socialización de la obra fue muy satisfactorio, ya que personas desde los 4 hasta los 75 años, disfrutaron viéndola y pudieron hacer una lectura del discurso desde su propia experiencia. La obra está diseñada para ser llevada a escena en espacios abiertos y cerrados, con el propósito de socializarla en cualquier condición física de la que se disponga.

La Danza Contemporánea es un lenguaje artístico social en cuanto necesita de la dinámica dialógica con el público para verificar su existencia. Una pieza que recree la 
experiencia particular del artista y que no permita identificar, evocar, reafirmar o rechazar intenciones del discurso (Pragmática del movimiento), no está cumpliendo con el encargo social del arte de construir cultura, en el sentido de generar procesos de pertenencia a un momento y lugar histórico determinados, que necesitan compartirse para ser identificados como sociales. Este diálogo permanente con el público como el interlocutor que retroalimenta los significados del hacer artístico desde sus significantes para reconocer al "otro", al artista y el artista al público como la única posibilidad de establecer ámbitos de comprensión mutua que garanticen la vida en colectivo, es una propuesta de interestructuración del hacer que ofrece Mutanza, desde su condición particular de Maestros - Bailarines, para cumplir con su proyecto de vida y su labor pedagógica en nuestra sociedad.

En la mayoría de los casos el coreógrafo es quien decide las condiciones de su obra, ya que él la ha creado. En nuestro caso particular, todo el proceso de creación y puesta en escena ha sido colectivo, pues el trabajo artístico obedece a un proyecto pedagógico didáctico del grupo.

\section{Bibliografía}

BERNARD, Michel. (1981). El Cuerpo. Técnicas y lenguajes corporales, Editorial Paidós.

CARDONA, Patricia. (1993). La percepción del espectador, CENDI - Danza, México D. F.

DENIS, Daniel. (1981). El cuerpo enseñado. Técnicas y lenguajes corporales, Editorial Paidós.

HOGHE, Raimund. Pina Bausch historias del teatro danza. Fotocopias.

HUMPHREY, Doris. La composición en la danza. Fotocopias.

MATOSO, Elina. (1996). El cuerpo, territorio escénico. Técnicas y lenguajes corporales. Editorial Paidós.

STOKOE, Patricia. (1994) La expresión corporal. Técnicas y lenguajes corporales. Editorial Paidós, Barcelona,

VARIOS AUTORES. (1991). Fragmentos para una historia del cuerpo humano. Taurus, Grupo Santillana, Madrid.

VON LABAN, Rudolf. (1984). El dominio del movimiento, Editorial Fundamentos.

ZAMACOIS, Joaquín. (1983). Teoría de la müsica, Libro 1 y 2, Editorial Labor. 